\title{
8p23.1 microdeletion syndrome
}

INSERM

\section{Source}

INSERM. (1999). Orphanet: an online rare disease and orphan drug data base. 8 p23.1 microdeletion syndrome. ORPHA:251071

8p23.1 deletion involves a partial deletion of the short arm of chromosome 8 characterized by low birth weight, postnatal growth deficiency, mild intellectual deficit, hyperactivity, craniofacial abnormalities, and congenital heart defects. 